\title{
Cardiovascular Event Risk in Rheumatoid Arthritis Compared with Type 2 Diabetes: A 15-year Longitudinal Study
}

\author{
Rabia Agca, Luuk H.G.A. Hopman, Koen J.C. Laan, Vokko P. van Halm, Mike J.L. Peters, \\ Yvo M. Smulders, Jacqueline M. Dekker, Giel Nijpels, Coen D.A. Stehouwer, \\ Alexandre E. Voskuyl, Maarten Boers $\mathbb{D}^{\mathbb{D}}$, Willem F. Lems, and Michael T. Nurmohamed
}

\begin{abstract}
Objective. Cardiovascular (CV) disease (CVD) risk is increased in rheumatoid arthritis (RA). However, longterm followup studies investigating this risk are scarce.

Methods. The CARRÉ (CARdiovascular research and RhEumatoid arthritis) study is a prospective cohort study investigating CVD and its risk factors in 353 patients with longstanding RA. CV endpoints were assessed at baseline and 3,10, and 15 years after the start of the study and are compared to a reference cohort $(n=2540)$, including a large number of patients with type 2 diabetes (DM).

Results. Ninety-five patients with RA developed a CV event over 2973 person-years, resulting in an incidence rate of 3.20 per 100 person-years. Two hundred fifty-seven CV events were reported in the reference cohort during 18,874 person-years, resulting in an incidence rate of 1.36 per 100 person-years. Age- and sex-adjusted HR for CV events were increased for RA (HR 2.07, 95\% CI $1.57-2.72, \mathrm{p}<0.01)$ and DM (HR 1.51, 95\% CI 1.02-2.22, $\mathrm{p}=0.04)$ compared to the nondiabetic participants. HR was still increased in RA (HR 1.82, 95\% CI 1.32-2.50, p < 0.01) after additional adjustment for CV risk factors. Patients with both RA and DM or insulin resistance had the highest HR for developing CVD $(2.21,95 \%$ CI 1.01-4.80, $\mathrm{p}=0.046$ and 2.67, 95\% CI 1.30-5.46, $\mathrm{p}<0.01$, respectively).

Conclusion. The incidence rate of CV events in established RA was more than double that of the general population. Patients with RA have an even higher risk of CVD than patients with DM. This risk remained after adjustment for traditional CV risk factors, suggesting that systemic inflammation is an independent contributor to CV risk. (First Release November 15 2019; J Rheumatol 2020;47:316-24; doi:10.3899/jrheum.180726)
\end{abstract}

Key Indexing Terms:

RHEUMATOID ARTHRITIS

CARDIOVASCULAR DISEASE

CARDIOVASCULAR RISK

TYPE 2 DIABETES MELLITUS

\begin{abstract}
From the Department of Rheumatology, Amsterdam Rheumatology and Immunology Center, Reade; Department of Rheumatology, Amsterdam Rheumatology and Immunology Center, VU University Medical Center; Department of Cardiology, and Department of Internal Medicine, and Department of Epidemiology and Biostatistics, and Department of General Practice, and EMGO Institute for Health and Care Research, Amsterdam UMC, VU University Medical Center; Amsterdam UMC, Academic Medical Center, Department of Cardiology; Department of Internal Medicine, and the Cardiovascular Research Institute Maastricht (CARIM), Maastricht University Medical Center, Maastricht, the Netherlands.
\end{abstract}

R. Agca, MD, Amsterdam Rheumatology and Immunology Center, Department of Rheumatology in Reade, and Amsterdam Rheumatology and Immunology Center, Department of Rheumatology, VU University Medical Center in Amsterdam; L.H. Hopman, PhD student, Amsterdam Rheumatology and Immunology Center, Department of Rheumatology; K.J. Laan, MD, Amsterdam Rheumatology and Immunology Center, Department of Rheumatology in Reade, and Amsterdam Rheumatology and Immunology Center, Department of Rheumatology, VU University Medical Center in Amsterdam; V.P. van Halm, MD, PhD, Amsterdam UMC, VU University Medical Center, Department of Cardiology, and Amsterdam UMC, Academic Medical Center, Department of Cardiology; M.J. Peters, MD, PhD, Amsterdam UMC, VU University Medical Center,

\begin{abstract}
Department of Internal Medicine; Y.M. Smulders, MD, Amsterdam UMC, VU University Medical Center, Department of Internal Medicine; J.M. Dekker, Prof. Dr., Amsterdam UMC, VU University Medical Center, Department of Epidemiology and Biostatistics; G. Nijpels, MD, Amsterdam UMC, VU University Medical Center, Department of General Practice, and Amsterdam UMC, VU University Medical Center, EMGO Institute for Health and Care Research; C.D. Stehouwer, MD, Maastricht University Medical Center, Department of Internal Medicine, and Maastricht University Medical Center, CARIM; A.E. Voskuyl, MD, Amsterdam Rheumatology and Immunology Center, Department of Rheumatology, VU University Medical Center; M. Boers, MD, Amsterdam UMC, VU University Medical Center, Department of Epidemiology and Biostatistics; W.F. Lems, MD, Amsterdam Rheumatology and Immunology Center, Department of Rheumatology, VU University Medical Center; M.T. Nurmohamed, MD, Amsterdam Rheumatology and Immunology Center, Department of Rheumatology in Reade, and Amsterdam Rheumatology and Immunology Center, Department of Rheumatology, VU University Medical Center in Amsterdam.

Address correspondence to Dr. R. Agca, Amsterdam Rheumatology and Immunology Center, VU University Medical Center \& Reade, P.O. Box 7057, 1007 MB Amsterdam, the Netherlands.

E-mail:r_agca@hotmail.com

Accepted for publication May 1, 2019.
\end{abstract}


Rheumatoid arthritis (RA) is associated with increased cardiovascular $(\mathrm{CV})$ morbidity and premature death of $\mathrm{CV}$ origin, when compared to the general population ${ }^{1}$. Several underlying mechanisms are suggested. Traditional $\mathrm{CV}$ risk factors are associated with the development of CVD in RA, similar to the general population ${ }^{1}$, including hypertension (HTN), dyslipidemia, smoking, type 2 diabetes, a sedentary lifestyle, and obesity. RA is characterized by chronic systemic inflammation (i.e., not limited to the joints), which is thought to be another major contributor to CVD development in these patients $^{2,3,4}$. Systemic inflammation appears to increase CV risk independently and beyond traditional CV risk factors, while it also potentially alters existing $\mathrm{CV}$ risk factors in these patients ${ }^{3,5,6}$. A metaanalysis of 14 observational cohort studies showed an overall increased CV risk of about $50 \%$ in patients with RA compared to non-RA participants ${ }^{7}$. Other studies report standardized mortality ratios (SMR) as high as 2.7 compared with the general population ${ }^{8,9}$; these SMR appear to be constant over 50 years ${ }^{10}$, although this has been challenged by a study reporting decreasing mortality in the last decade ${ }^{11}$. However, study results are heterogeneous, and most studies have a followup shorter than 10 years. In 2009, our group also reported an increased CV risk in a cohort of patients with RA compared with a population-based reference cohort over 3 years of followup ${ }^{4}$. We now report on the incidence and risk of fatal and non-fatal CV events in this cohort over a maximum followup period of 15 years, compared with a representative sample cohort of the general population focusing on prevalence and incidence of type 2 diabetes mellitus (DM) and its complications.

\section{MATERIALS AND METHODS}

To investigate the risk of incident CVD in participants with RA versus DM and the general population, the CARRÉ (CARdiovascular research and RhEumatoid arthritis) study cohort and the Hoorn study cohort were compared. In both populations, data regarding demographics, RA-related variables, risk factors for $C V D$, and new or incident $C V$ events after the start of the study were collected. A brief description of both study cohorts follows. The CARRÉ study. The CARRÉ study was initiated in 2000 with the purpose of investigating CVD and its risk factors in patients with longstanding RA. As previously described by van Halm, et $a l^{12}$, patients were eligible for participation if they were registered at the Jan van Breemen Institute (Reade since 2009) in Amsterdam, the Netherlands, fulfilled the 1987 American College of Rheumatology classification criteria, were diagnosed with RA between 1989 and 2001, and were aged between 50 and 75 years. Patient enrollment was done between January 2001 and January 2002. In total, 353 patients with RA were followed prospectively for 15 years. Study assessments were performed at baseline, 3 years (2004-2005), and 10 years of follow up (2010-2011). Participants were called for a CVD questionnaire in 2015 (15 yrs of followup) to assess the occurrence of CV events during the study period. All reported events since the start of the study were confirmed with medical records.

The Hoorn study. The Hoorn study is a Dutch cohort study of glucose metabolism and other CV risk factors that began in $1989^{13}$. The cohort and its baseline measurements have been described in detail previously ${ }^{14}$. Briefly, a random selection of 3553 men and women, 50-75 years old, was taken from the population register. A total of 2540 (71.5\%) agreed to participate, and after the exclusion of 56 non-white participants, the Hoorn Study population consisted of 2484 men and women. All Hoorn participants were subject to an extensive and repeated CV screening program similar to that used in our CARRÉ study. The local Medical Ethics Committee approved both studies (METc VUmc, Amsterdam, The Netherlands, 2001.198) and all participants gave their written informed consent at the baseline visit. An overview of the 2 cohorts is shown in Figure 1.

Assessment of RA-related values. At baseline, the demographic data, medical history, family history, and medication use of all patients with RA were recorded. Additionally, the Health Assessment Questionnaire was performed and a Disease Activity Score of 28 joints (DAS28) was calculated. IgM-rheumatoid factor (IgM-RF) and anticitrullinated protein antibody (ACPA) were assessed only at baseline. Assessed at all visits were $\mathrm{C}$-reactive protein, erythrocyte sedimentation rate, and the presence of erosions in hands and feet with radiographs.

Assessment of traditional CV risk factors. CV risk factors were assessed for all subjects according to identical protocols in both studies, as described previously ${ }^{4}$. The assessments included smoking status, systolic and diastolic blood pressure (BP), body mass index (BMI; weight $/$ height ${ }^{2}$ in $\mathrm{kg} / \mathrm{m}^{2}$ ), waist to hip ratio and in fasting blood samples total cholesterol (TC), high-density lipoprotein cholesterol (HDL-C), low-density lipoprotein cholesterol (LDL-C), triglycerides (TG), TC/HDL-C ratio, glucose, HbA1c, and creatinine. HTN was defined as a systolic BP above $140 \mathrm{mmHg}$ and/or a diastolic BP above $90 \mathrm{mmHg}$ and/or current use of antihypertensive agents. DM was assessed in both study cohorts according to the 1999 World Health Organization criteria ${ }^{15}$. Patients were grouped according to fasting glucose levels into normal fasting glucose $<6.1 \mathrm{mmol} / 1(<110 \mathrm{mg} / \mathrm{dl})$, impaired fasting glucose (IFG), or insulin resistance (IR) $\geq 6.1$ to $<7.0 \mathrm{mmol} / 1$ (110-125 mg/dl), and DM if glucose $\geq 7.0 \mathrm{mmol} / 1$ ( $\geq 126 \mathrm{mg} / \mathrm{dl})$ or treated with glucose-lowering agents.

Assessment of CVD. Prevalent CVD at baseline and incident fatal and nonfatal CV events at followup were registered separately according to the International Classification of Diseases, 9th ed (ICD-9 codes 410.0-410.9, $435.9,436,443.9$, and 798). CVD was defined as a verified medical history of coronary heart disease (i.e., myocardial infarction, percutaneous coronary intervention, coronary angiography with significant stenosis, stent placement, or coronary artery bypass graft), cerebral arterial disease (e.g., cerebrovascular accident, transient ischemic attack, or carotid endarterectomy), or peripheral arterial disease (e.g., ankle brachial pressure index $<0.50$, peripheral arterial reconstructive surgery, or limb amputation). Unexpected deaths were considered to be CV mortality only when this was confirmed by autopsy. After study entry, participants were censored after the first new fatal or nonfatal CV event or death due to other reasons. CV events before baseline (prevalent CVD) in medical records of study participants were registered separately for additional correction in statistical analyses but were not used as new incident $\mathrm{CV}$ event cases for the primary outcome. The remaining patients were censored at study cessation time: March 1, 2015. Only the first $\mathrm{CV}$ event during followup was recorded. Patients lost to followup were censored at date of their last (event-free) followup visit. To extract data on the occurrence of $\mathrm{CV}$ events of the patients lost to followup, medical records were searched for the most recent medical status.

Statistical analysis. The baseline characteristics of both study cohorts were compared with parametric and nonparametric tests as appropriate. Incidence rates for fatal and nonfatal $\mathrm{CV}$ events were calculated per 100 person-years. The risk of developing CV events was compared between RA patients without DM, the nondiabetic general population, and patients with DM but without RA by calculating HR with Cox proportional hazards models. These hazard models were adjusted for potential confounders identified at baseline and in earlier studies ${ }^{4}$. Prevalent CVD was not excluded from the analyses, except where stated otherwise. Figure 2 was created using the corrected group prognosis method as described by Ghali, et al ${ }^{16}$. Several hazard models were made: the first model corrected adjusted for age and sex; the second model additionally adjusted corrected for systolic BP, use of antihypertensive agents, TC, HDL-C, statin use, smoking in pack-years, BMI, and aspirin use. The HR were first calculated for all patients. In the

Personal non-commercial use only. The Journal of Rheumatology Copyright (C) 2020. All rights reserved. 


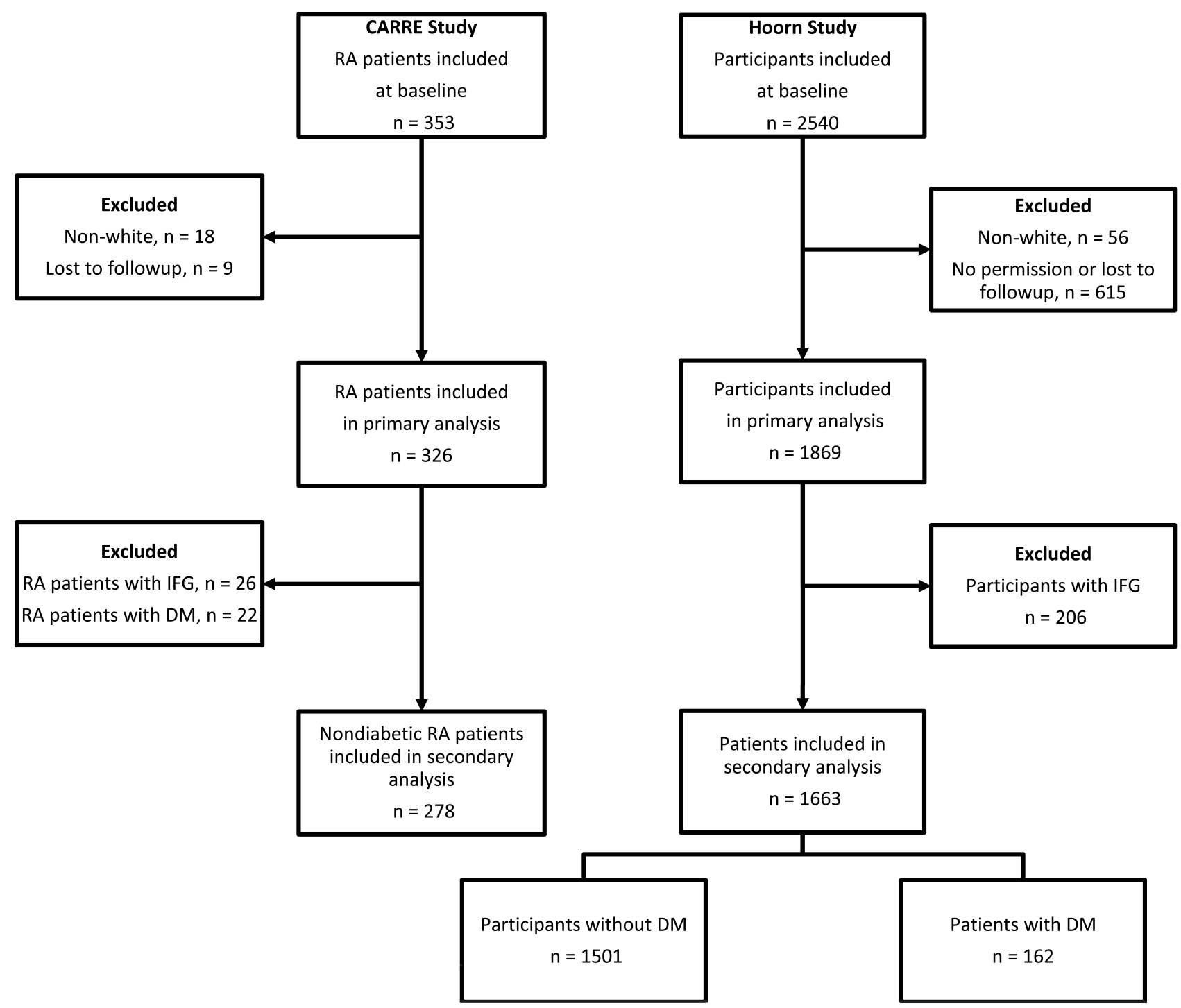

Figure 1. Study design of the CARRÉ and Hoorn study cohorts. RA: rheumatoid arthritis; IFG: impaired fasting glucose; DM: type 2 diabetes mellitus.

secondary analysis, patients with prevalent CVD were excluded. Additionally, the risk of developing CV events in patients with both RA and type $2 \mathrm{DM}$ was compared to the other groups of patients. All analyses were performed with the software package IBM SPSS statistics (version 19). A $\mathrm{p}$ value $<0.05$ was considered statistically significant.

\section{RESULTS}

Baseline characteristics of both study populations. In the CARRÉ study, of the 353 patients with RA at baseline, 326 patients were included in the primary analyses (Figure 1). Their baseline characteristics as well as those from the Hoorn study reference cohort are shown in Table 1. Of these, 27 were lost to followup later on in the study because of migration, not wishing to participate because of a high burden, or death. The median followup duration was 11 years, with a minimum of 2 months and a maximum of 15 years.
The majority of the patients with RA was female (65\%) with a mean age of $63 \pm 7$ years. The median disease duration was 7 (4-10) years with a mean DAS28 score of $3.9 \pm 1.3$. Of the patients, $236(72 \%)$ were IgM-RF-positive, 168 (52\%) were ACPA-positive, and $263(81 \%)$ had erosions in the hands or feet. Patients with RA were slightly older than the reference cohort and had more often prevalent CVD (15\% vs $7 \%$ ), HTN (61\% vs $32 \%$ ), a longer cumulative exposure to smoking, and more often used antihypertensive drugs, statins, or aspirin.

New $C V$ events in $R A$ versus the general population. In the CARRÉ study, 95 patients developed a CV event during a median followup period of 11 years (range 2 mos to $15 \mathrm{yrs}$ ) and a total followup time of 2973 patient-years, resulting in a CVD incidence rate of 3.20 per 100 person-years (Table 2). 

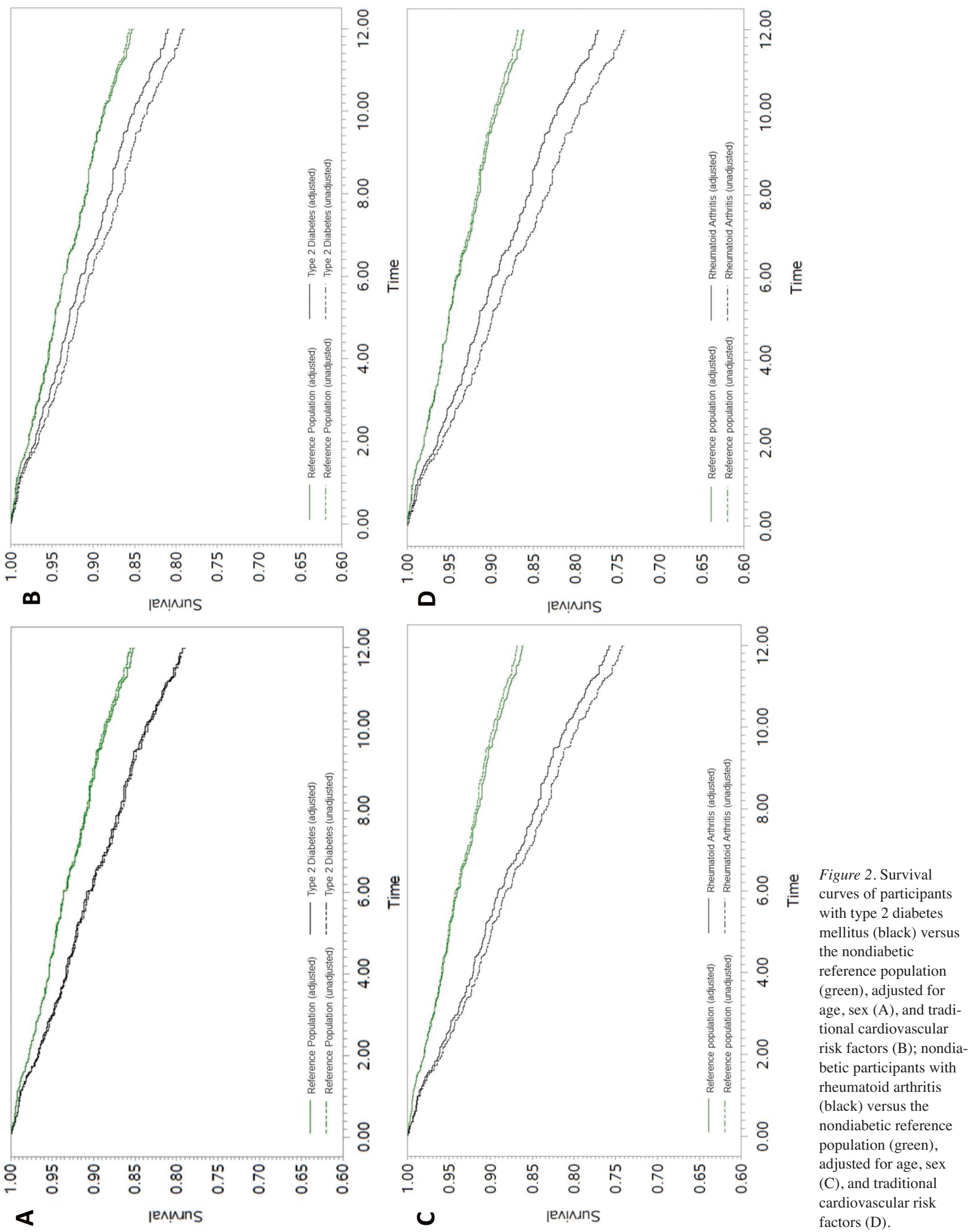

Personal non-commercial use only. The Journal of Rheumatology Copyright @ 2020 . All rights reserved. 
Table 1. Patient characteristics of the RA population and the reference cohort at baseline.

\begin{tabular}{|c|c|c|}
\hline Characteristics & RA Population, $\mathrm{n}=326$ & Reference Cohort, $\mathrm{n}=1869$ \\
\hline \multicolumn{3}{|l|}{ Demographics } \\
\hline Age, yrs & $63 \pm 7^{*}$ & $62 \pm 7$ \\
\hline Women, n (\%) & $212(65)^{*}$ & $976(52)$ \\
\hline Median inclusion yr & 2002 & 1991 \\
\hline Followup duration, yrs & $11.2(6.1-12.4)$ & $12(9.5-12.0)$ \\
\hline \multicolumn{3}{|l|}{$\mathrm{CV}$ risk factors } \\
\hline Previous CVD, n (\%) & $48(15)^{*}$ & $123(7)$ \\
\hline Hypertension, $\mathrm{n}(\%)$ & $200(61)^{*}$ & $601(32)$ \\
\hline \multicolumn{3}{|l|}{ Smoking, n (\%) } \\
\hline Never & $71(22)^{*}$ & $630(34)$ \\
\hline Former smoker & $159(49)^{*}$ & $666(36)$ \\
\hline Current smoker & $96(29)^{*}$ & $562(30)$ \\
\hline Pack-yrs & $18(2-38)^{*}$ & $12(0-28)$ \\
\hline \multicolumn{3}{|l|}{ Glucose status, n (\%) } \\
\hline Normal fasting glucose levels & $283(87)$ & $1501(80)$ \\
\hline IFG levels & $26(8)$ & $206(11)$ \\
\hline $\mathrm{DM}$ & $16(5)$ & $162(9)$ \\
\hline Known/newly diagnosed DM & $14 / 8$ & $73 / 89$ \\
\hline Systolic BP, mmHg & $142 \pm 20^{*}$ & $135 \pm 20$ \\
\hline Diastolic BP, mmHg & $81 \pm 8^{*}$ & $82 \pm 10$ \\
\hline $\mathrm{TC}, \mathrm{mmol} / \mathrm{l}$ & $5.79 \pm 1.13^{*}$ & $6.63 \pm 1.16$ \\
\hline HDL-C, mmol/l & $1.45 \pm 0.49^{*}$ & $1.32 \pm 0.37$ \\
\hline LDL-C, mmol/1 & $3.71 \pm 1.04 *$ & $4.59 \pm 1.06$ \\
\hline Triglycerides, mmol/1 & $1.32(0.96-1.84)$ & $1.40(1.00-1.90)$ \\
\hline TC/HDL-C ratio & $4.38 \pm 1.55^{*}$ & $5.36 \pm 1.72$ \\
\hline Waist/hip ratio & $0.9 \pm 0.1$ & $0.9 \pm 0.1$ \\
\hline Body mass index, $\mathrm{kg} / \mathrm{m}^{2}$ & $26.7 \pm 4.8$ & $26.5 \pm 3.4$ \\
\hline \multicolumn{3}{|l|}{ Medication, n (\%) } \\
\hline Antihypertensive drugs & $84(26)^{*}$ & $373(20)$ \\
\hline Statins & $37(11)^{*}$ & $29(2)$ \\
\hline Aspirin & $54(17)^{*}$ & $62(3)$ \\
\hline \multicolumn{3}{|l|}{ RA-related factors } \\
\hline Age at RA diagnosis, yrs & $55 \pm 8$ & - \\
\hline Disease duration, yrs & $7(4-10)$ & - \\
\hline $\mathrm{IgM}-\mathrm{RF} \geq 30 \mathrm{U} / \mathrm{ml}, \mathrm{n}(\%)$ & $236(72)$ & - \\
\hline $\mathrm{ACPA} \geq 50 \mathrm{kU} / \mathrm{l}, \mathrm{n}(\%)$ & $168(52)$ & - \\
\hline Erosion on radiographs, $\mathrm{n}(\%)$ & $263(81)$ & - \\
\hline DAS28, range $0-10$ & $3.9 \pm 1.3$ & - \\
\hline NSAID, n $(\%)$ & $218(67)$ & - \\
\hline Biologic agents, $\mathrm{n}(\%)$ & $33(10)$ & - \\
\hline Methotrexate, n (\%) & $195(60)$ & - \\
\hline Prednisone, n (\%) & $54(17)$ & - \\
\hline Sulfasalazine, n (\%) & $53(16)$ & - \\
\hline Hydroxychloroquine, n (\%) & $24(7)$ & - \\
\hline Leflunomide, n (\%) & $27(8)$ & - \\
\hline Other DMARD, n (\%) & $20(6)$ & - \\
\hline
\end{tabular}

Continuous variables are presented as mean $\pm \mathrm{SD}$ or median (interquartile range). Categorical and dichotomous variables are presented as numbers and/or percentages. *Significantly different from the general population. CV: cardiovascular; CVD: CV disease; BP: blood pressure; TC: total cholesterol; LDL-C: low-density lipoprotein cholesterol; HDL-C: high-density lipoprotein cholesterol; pack-yrs: (packs smoked per day) $\times$ (years as a smoker); IFG: impaired fasting glucose; DM: type 2 diabetes mellitus; RA: rheumatoid arthritis; IgM-RF: immunoglobulin M rheumatoid factor; ACPA: anticitrullinated protein antibody; DAS28: Disease Activity Score at 28 joints; DMARD: disease-modifying antirheumatic drug; NSAID: nonsteroidal antiinflammatory drug.

In the Hoorn study, 257 participants developed a CV event during 12 years of median followup (range 1 mo to 12 yrs) and a total followup time of 18,874 patient-years, resulting in a CVD incidence rate of 1.36 per 100 person-years (Table
2). The occurring CV event subtypes are described in Appendix 1. Age- and sex-adjusted Cox regression analyses showed an HR of 1.93 (95\% CI 1.51-2.45, p < 0.01) for CV events in RA (Table 2). Additional adjustment for CV risk 
Table 2. HR for new CV events in patients with RA versus the reference population.

\begin{tabular}{|c|c|c|c|}
\hline Characteristics & RA Population & Reference Population & $\mathrm{p}$ \\
\hline All patients, $n$ & 326 & 1869 & \\
\hline Total followup, yrs & 2973 & 18,874 & \\
\hline Fatal and nonfatal CV events, $\mathrm{n}$ & 95 & 257 & \\
\hline Incidence per 100 person-yrs & 3.20 & 1.36 & \\
\hline \multicolumn{4}{|l|}{ HR RA vs reference cohort } \\
\hline Model 1* & $1.93(1.51-2.45)$ & 1.00 & $<0.01$ \\
\hline Model $2^{\#}$ & $1.89(1.40-2.46)$ & 1.00 & $<0.01$ \\
\hline Patients with prevalent $\mathrm{CVD}^{\Delta}$ excluded, $\mathrm{n}$ & 278 & 1746 & \\
\hline Total followup, yrs & 2627 & 18,008 & \\
\hline Fatal and nonfatal CV event, $\mathrm{n}$ & 69 & 225 & \\
\hline Incidence per 100 person-yrs & 2.63 & 1.25 & \\
\hline \multicolumn{4}{|l|}{ HR RA vs reference cohort } \\
\hline Model 1* & $1.75(1.31-2.32)$ & 1.00 & $<0.01$ \\
\hline Model $2^{\#}$ & $1.96(1.45-2.66)$ & 1.00 & $<0.01$ \\
\hline
\end{tabular}

*Adjusted for age and sex. ${ }^{\# A d j u s t e d ~ f o r ~ a g e, ~ s e x, ~ s y s t o l i c ~ b l o o d ~ p r e s s u r e, ~ a n t i h y p e r t e n s i v e ~ a g e n t s, ~ t o t a l ~ c h o l e s t e r o l, ~}$ high-density lipoprotein cholesterol, statins, smoking in pack-years, body mass index, diabetes mellitus, and aspirin. ${ }^{\triangle} \mathrm{CVD}$ according to the International Classification of Diseases criteria. $\mathrm{CV}$ : cardiovascular; RA: rheumatoid arthritis; CVD: CV disease.

factors resulted in an HR of 1.89 (95\% CI 1.40-2.46, p <0.01). Adjustment for prednisone use did not affect the HR significantly (data not shown). Exclusion of patients with prevalent CVD at baseline resulted in comparable HR (Table 2).

New CV event in RA and DM versus the reference population and in RA versus DM. Before conducting these analyses, RA patients with an IFG $(n=26)$ or already diagnosed with DM $(n=22)$ were excluded from the CARRÉ study, and patients with an IFG $(n=206)$ were excluded from the Hoorn study. Cox regression analyses comparing incident $\mathrm{CV}$ events were performed with the remaining participants grouped into nondiabetic RA $(n=278), D M(n=162)$, and the nondiabetic reference population $(n=1501$; Table 3$)$. The HR was increased for RA (HR 2.07, 95\% CI 1.57-2.72, p < 0.01 ) and DM (HR 1.51, 95\% CI 1.02-2.22, p = 0.04) in the age- and sex-adjusted model (Table 3, Figure 2). After adjustment for CV risk factors, the $\operatorname{HR}(1.82,95 \%$ CI 1.32-2.50, $\mathrm{p}<0.01)$ remained significantly increased in RA while it was not significant in DM (HR 1.28, 95\% CI 0.85-1.92, p = 0.25; Table 3, Figure 2), with similar results after exclusion of patients with prevalent CVD (Table 3 ). The adjusted survival curves of the nondiabetic reference population, participants with DM, and nondiabetic participants with RA are shown in Figure 2. In addition, a direct comparison between participants with RA $(n=278)$ and participants with DM $(n=162)$ showed a higher HR for CVD in RA when compared to DM (age- and sex-adjusted HR 1.64, 95\% CI 1.07-2.53, p=0.02). New $C V$ events in subgroups of $R A$, insulin resistance, and $D M$ versus the general population. The risk of developing $\mathrm{CV}$ events was compared between the nondiabetic general population ( $n=1501)$, individuals with IR $(n=206)$, individuals with DM ( $\mathrm{n}=162)$, participants with RA but without IR or DM ( $\mathrm{n}=278)$, study participants with RA and IR $(n=26)$, and participants with RA and DM $(n=22)$.
Table 3. New CV events in RA and DM versus the reference population.

\begin{tabular}{lccc}
\hline Patients & HR & $95 \%$ CI & p \\
\hline All patients & & & \\
$\quad$ Model 1 & & & \\
$\quad$ Nondiabetic population & 1.00 & Reference & - \\
$\quad$ DM & 1.51 & $1.02-2.22$ & 0.04 \\
$\quad$ Nondiabetic patients with RA & 2.07 & $1.57-2.72$ & $<0.01$ \\
$\quad$ Model 2 & & & \\
$\quad$ Nondiabetic population & 1.00 & Reference & - \\
$\quad$ DM & 1.28 & $0.85-1.92$ & 0.25 \\
$\quad$ Nondiabetic patients with RA & 1.82 & $1.32-2.50$ & $<0.01$ \\
Patients with prevalent CVD excluded & & & \\
$\quad$ Model 1 & & & \\
$\quad$ Nondiabetic population & 1.00 & Reference & - \\
$\quad$ DM & 1.42 & $0.92-2.21$ & 0.12 \\
$\quad$ Nondiabetic patients with RA & 1.82 & $1.32-2.50$ & $<0.01$ \\
$\quad$ Model 2 & & & \\
$\quad$ Nondiabetic population & 1.00 & Reference & - \\
$\quad$ DM & 1.15 & $0.72-1.84$ & 0.56 \\
$\quad$ Nondiabetic patients with RA & 1.96 & $1.39-2.78$ & $<0.01$ \\
\hline
\end{tabular}

Model 1: adjusted for age and sex. Model 2: adjusted for age, sex, systolic blood pressure, antihypertensive agents, total cholesterol, high-density lipoprotein cholesterol, statins, smoking in pack-years, body mass index, and aspirin. CV: cardiovascular; CVD: CV disease; RA: rheumatoid arthritis; DM: type 2 diabetes mellitus.

Compared to the nondiabetic general population, patients with RA and IR had the highest risk of developing a CV event when the hazard model was corrected for age and sex, followed by the other patients with RA (Table 4). Results were similar after additional correction for systolic BP, antihypertensive agents, TC, HDL-C, statin use, smoking, $\mathrm{BMI}$, aspirin use, and prevalent CVD.

$$
\text { Personal non-commercial use only. The Journal of Rheumatology Copyright @ } 2020 \text {. All rights reserved. }
$$


Table 4. New CV events in RA with IR and DM versus the reference population.

\begin{tabular}{lccc}
\hline All Patients & HR & $95 \%$ CI & $\mathrm{p}$ \\
\hline Model 1 & & & \\
$\quad$ Reference population, normal & & & \\
$\quad$ glucose tolerance & 1.00 & Reference & - \\
Insulin resistance & 1.46 & $1.04-2.07$ & 0.03 \\
DM & 1.51 & $1.03-2.23$ & 0.04 \\
RA & & & \\
$\quad$ Normal glucose tolerance & 2.08 & $1.58-2.74$ & $<0.01$ \\
$\quad$ Insulin resistance & 2.70 & $1.33-5.49$ & $<0.01$ \\
$\quad$ DM & 2.23 & $1.04-4.75$ & 0.04 \\
Model 2 & & & \\
Reference population, normal & & & \\
$\quad$ glucose tolerance & 1.00 & Reference & - \\
Insulin resistance & 1.18 & $0.82-1.70$ & 0.37 \\
DM & 1.30 & $0.87-1.95$ & 0.20 \\
RA & & & $<0.01$ \\
$\quad$ Normal glucose tolerance & 1.89 & $1.37-2.56$ & $<0.01$ \\
$\quad$ Insulin resistance & 2.67 & $1.30-5.46$ & 0.046 \\
DM & 2.21 & $1.01-4.80$ & \\
\hline
\end{tabular}

Model 1: adjusted for age and sex. Model 2: adjusted for age, sex, systolic blood pressure, antihypertensive agents, total cholesterol, high-density lipoprotein cholesterol, statins, smoking in pack-years, body mass index, aspirin, and prevalent $\mathrm{CV}$ disease. CV: cardiovascular; RA: rheumatoid arthritis; IR: insulin resistance; DM: type 2 diabetes mellitus.

\section{DISCUSSION}

In our second report on this cohort, now with a median followup of 11 years, the increased risk of CVD in RA already seen after 3 years of followup ${ }^{4}$ was confirmed, now at a level more than double that of the nondiabetic general population. Traditional CV risk factors, such as HTN, smoking, older age, and previous CVD partially explained this increased risk. However, the Cox proportional hazard models adjusted for these risk factors still showed an almost 2-fold increased CV risk in participants with RA. In participants with DM, the increased CV risk was almost fully explained by traditional CV risk factors. In RA, high-grade systemic inflammation most likely amplifies $\mathrm{CV}$ risk, as suggested previously ${ }^{3,4,5}$. Recently, Curtis, et al reported the highest incidence rate of acute myocardial infarction in patients with RA and DM, followed by patients with DM only, RA only, and neither RA nor DM ${ }^{17}$. We found similar results (highest HR) for participants with RA and IR or DM, but in our study, participants with RA only had a higher CVD risk than participants with DM only. This might be explained by differences in study design and population and definitions of CVD outcome. More importantly, both studies underline and establish that RA is a risk factor for the development of CVD.

Interestingly, although we had a low number of observations, the risk of IR or DM appeared additive to that of RA, suggesting that in such patients, risk factors should be approached aggressively. In participants with RA, levels of TC, LDL-C, and TG were lower than in the nondiabetic general population, while HDL-C was higher. In the past, several publications have described this phenomenon as the "lipid paradox," in which the above-mentioned observation is not translated into a lower but paradoxically into a higher $\mathrm{CV}$ risk in patients with $\mathrm{RA}^{18,19,20}$. However, we identified an increased CVD risk in RA, regardless of the effect of these lipid changes on this $\mathrm{CV}$ risk, because we adjusted for TC, HDL-C, and statin use in our analyses. Optimal treatment of RA results in a normalization of lipid levels in these patients $21,22,23,24$. Unfortunately, our study also demonstrates that, although patients with RA have an increased presence of certain known risk factors for CVD, only a small proportion of patients with RA is receiving appropriate treatment with antihypertensive agents and statins. This finding is also in line with other studies ${ }^{25,26,27,28}$, suggesting that appropriate management of lifestyle factors and CV risk factors is lacking in these patients. Possible explanations could be that local $\mathrm{CV}$ risk management programs are ineffective or that patients and physicians are unaware of the magnitude of this risk. In addition, current $\mathrm{CV}$ risk assessment tools are inaccurate and risk assessment is performed using general population algorithms (e.g., SCORE and Framingham Risk Score). Some risk factors, such as lipids, are influenced by inflammation and are not an appropriate indicator for $\mathrm{CV}$ risk during periods of active disease ${ }^{20}$. Therefore, $\mathrm{CV}$ risk algorithms that accurately predict $\mathrm{CV}$ risk in RA as well as multidisciplinary $\mathrm{CV}$ risk assessment and management are certainly of additional value. Above all, creating awareness of this increased $\mathrm{CV}$ risk among patients and clinicians is of great importance.

The major strength of our study is its long followup duration in which the occurrence of both fatal and nonfatal $\mathrm{CV}$ events was recorded in patients with RA and in the general population. Our previous study had a followup duration of only 3 years, with few events, resulting in limited power, but in our current study the longterm observation and the number of events was sufficient to overcome this. However, our present study also has some limitations. The Hoorn study was conducted about 10 years before the CARRÉ study. The definition of certain diseases, their assessment, and management may have changed during this period. This may have influenced our results. Additionally, CVD incidence has declined over the last decades in the Netherlands, which could translate into less incident CVD in patients with $\mathrm{RA}^{29}$. However, comparing both groups would in this case lead to an underestimation of the CV risk in patients with RA. Additionally, the Hoorn study may have included some patients with RA that we could not identify because of insufficient data, but this would also only result in an underestimation of the $\mathrm{CV}$ risk in RA. Another important matter is that the prevalence of MTX and biologic treatment at baseline is not representative of the current clinical practice. Treatment guidelines have changed over the last decade and this could have influenced the CVD incidence in the RA population. However, the effect of antirheumatic

Personal non-commercial use only. The Journal of Rheumatology Copyright (C) 2020. All rights reserved. 
treatment on CVD risk in patients with RA was not the research question of our study.

Our study demonstrates a more than 2-fold higher CV risk in patients with RA when compared with the nondiabetic general population. In our study, this risk is even higher than the CV risk of patients with DM. In accordance with our previous study from $2009^{4}$, adjustment for CV risk factors still results in a significant residual CVD risk for patients with RA, indicating that systemic inflammation is likely an independent contributor to $\mathrm{CV}$ risk in RA. This underscores that both optimal antiinflammatory treatment of RA as well as effective $\mathrm{CV}$ risk management are likely of major importance to reduce $\mathrm{CV}$ risk in these patients.

\section{REFERENCES}

1. Agca R, Heslinga SC, van Halm VP, Nurmohamed MT. Atherosclerotic cardiovascular disease in patients with chronic inflammatory joint disorders. Heart 2016;102:790-5.

2. Lindhardsen J, Ahlehoff O, Gislason GH, Madsen OR, Olesen JB, Torp-Pedersen $\mathrm{C}$, et al. The risk of myocardial infarction in rheumatoid arthritis and diabetes mellitus: a Danish nationwide cohort study. Ann Rheum Dis 2011;70:929-34.

3. Myasoedova E, Chandran A, Ilhan B, Major BT, Michet CJ, Matteson EL, et al. The role of rheumatoid arthritis (RA) flare and cumulative burden of RA severity in the risk of cardiovascular disease. Ann Rheum Dis 2016;75:560-5.

4. Peters MJ, van Halm VP, Voskuyl AE, Smulders YM, Boers M, Lems WF, et al. Does rheumatoid arthritis equal diabetes mellitus as an independent risk factor for cardiovascular disease? A prospective study. Arthritis Rheum 2009;61:1571-9.

5. Innala L, Möller B, Ljung L, Magnusson S, Smedby T, Södergren A, et al. Cardiovascular events in early RA are a result of inflammatory burden and traditional risk factors: a five year prospective study. Arthritis Res Ther 2011;13:R131.

6. Zhang J, Chen L, Delzell E, Muntner P, Hillegass WB, Safford MM, et al. The association between inflammatory markers, serum lipids and the risk of cardiovascular events in patients with rheumatoid arthritis. Ann Rheum Dis 2014;73:1301-8.

7. Avina-Zubieta JA, Thomas J, Sadatsafavi M, Lehman AJ, Lacaille D. Risk of incident cardiovascular events in patients with rheumatoid arthritis: a meta-analysis of observational studies. Ann Rheum Dis 2012;71:1524-9.

8. Symmons DP, Jones MA, Scott DL, Prior P. Longterm mortality outcome in patients with rheumatoid arthritis: early presenters continue to do well. J Rheumatol 1998;25:1072-7.

9. Wolfe F, Mitchell DM, Sibley JT, Fries JF, Bloch DA, Williams CA, et al. The mortality of rheumatoid arthritis. Arthritis Rheum 1994;37:481-94.

10. Meune C, Touzé E, Trinquart L, Allanore Y. Trends in cardiovascular mortality in patients with rheumatoid arthritis over 50 years: a systematic review and meta-analysis of cohort studies. Rheumatology 2009;48:1309-13.

11. Myasoedova E, Gabriel SE, Matteson EL, Davis JM 3rd, Therneau TM, Crowson CS. Decreased cardiovascular mortality in patients with incident rheumatoid arthritis (RA) in recent years: dawn of a new era in cardiovascular disease in RA? J Rheumatol 2017; 44:732-9.

12. van Halm VP, Peters MJ, Voskuyl AE, Boers M, Lems WF, Visser $\mathrm{M}$, et al. Rheumatoid arthritis versus diabetes as a risk factor for cardiovascular disease: a cross-sectional study, the CARRE Investigation. Ann Rheum Dis 2009;68:1395-400.

13. Rijkelijkhuizen JM, Nijpels G, Heine RJ, Bouter LM, Stehouwer
CD, Dekker JM. High risk of cardiovascular mortality in individuals with impaired fasting glucose is explained by conversion to diabetes: the Hoorn study. Diabetes Care 2007;30:332-6.

14. Mooy JM, Grootenhuis PA, de Vries H, Valkenburg HA, Bouter LM, Kostense PJ, et al. Prevalence and determinants of glucose intolerance in a Dutch Caucasian population. The Hoorn Study. Diabetes Care 1995;18:1270-3.

15. Gabir MM, Hanson RL, Dabelea D, Imperatore G, Roumain J, Bennett PH, et al. Plasma glucose and prediction of microvascular disease and mortality: evaluation of 1997 American Diabetes Association and 1999 World Health Organization criteria for diagnosis of diabetes. Diabetes Care 2000;23:1113-8.

16. Ghali WA, Quan H, Brant R, van Melle G, Norris CM, Faris PD, et al; APPROACH (Alberta Provincial Project for Outcome Assessment in Coronary Heart Disease) Investigators. Comparison of 2 methods for calculating adjusted survival curves from proportional hazards models. JAMA 2001;286:1494-7.

17. Curtis JR, Yang S, Singh JA, Xie F, Chen L, Yun H, et al. Is rheumatoid arthritis a cardiovascular risk-equivalent to diabetes? Arthritis Care Res 2018;70:1694-9.

18. Boyer JF, Bongard V, Cantagrel A, Jamard B, Gottenberg JE, Mariette $\mathrm{X}$, et al. Link between traditional cardiovascular risk factors and inflammation in patients with early arthritis: results from a French multicenter cohort. Arthritis Care Res 2012; 64:872-80.

19. Liao KP, Solomon DH. Traditional cardiovascular risk factors, inflammation and cardiovascular risk in rheumatoid arthritis. Rheumatology 2013;52:45-52.

20. Myasoedova E, Crowson CS, Kremers HM, Roger VL, Fitz-Gibbon PD, Therneau TM, et al. Lipid paradox in rheumatoid arthritis: the impact of serum lipid measures and systemic inflammation on the risk of cardiovascular disease. Ann Rheum Dis 2011;70:482-7.

21. Curtis JR, John A, Baser O. Dyslipidemia and changes in lipid profiles associated with rheumatoid arthritis and initiation of anti-tumor necrosis factor therapy. Arthritis Care Res 2012; 64:1282-91.

22. Daïen CI, Duny Y, Barnetche T, Daurès JP, Combe B, Morel J. Effect of TNF inhibitors on lipid profile in rheumatoid arthritis: a systematic review with meta-analysis. Ann Rheum Dis 2012;71:862-8.

23. Filippatos TD, Derdemezis CS, Voulgari PV, Tsimihodimos V, Elisaf MS, Tselepis AD, et al. Effects of 12 months of treatment with disease-modifying anti-rheumatic drugs on low and high density lipoprotein subclass distribution in patients with early rheumatoid arthritis: a pilot study. Scand J Rheumatol 2013;42:169-75.

24. Georgiadis AN, Voulgari PV, Argyropoulou MI, Alamanos Y, Elisaf M, Tselepis AD, et al. Early treatment reduces the cardiovascular risk factors in newly diagnosed rheumatoid arthritis patients. Semin Arthritis Rheum 2008;38:13-9.

25. Panoulas VF, Douglas KM, Milionis HJ, Stavropoulos-Kalinglou A, Nightingale P, Kita MD, et al. Prevalence and associations of hypertension and its control in patients with rheumatoid arthritis. Rheumatology 2007;46:1477-82.

26. Primdahl J, Clausen J, Horslev-Petersen K. Results from systematic screening for cardiovascular risk in outpatients with rheumatoid arthritis in accordance with the EULAR recommendations. Ann Rheum Dis 2013;72:1771-6.

27. Toms TE, Panoulas VF, Douglas KM, Griffiths H, Sattar N, Smith JP, et al. Statin use in rheumatoid arthritis in relation to actual cardiovascular risk: evidence for substantial undertreatment of lipid-associated cardiovascular risk? Ann Rheum Dis 2010; 69:683-8.

28. van den Oever IAM, Heslinga M, Griep EN, Griep-Wentink HRM, Schotsman R, Cambach W, et al. Cardiovascular risk management in rheumatoid arthritis patients still suboptimal: the Implementation

Personal non-commercial use only. The Journal of Rheumatology Copyright $\subset$ 2020. All rights reserved. 
of Cardiovascular Risk Management in Rheumatoid Arthritis project. Rheumatology 2017;56:1472-8.

29. Bots ML, Buddeke J, van Dis I, Vaartjes I, Visseren FLJ.

[Cardiovascular disease in the Netherlands 2015]. [Report in Dutch]
Dutch Heart Foundation. [Internet. Accessed October 17, 2019.]

Available from: https://www.hartstichting.nl/getmedia/

b9b5f9df-d00e-44da-bcdd-053d1c18dc07/

cijferboek-hartstichting-hart-vaatziekten-nederland-2015.pdf

APPENDIX 1. Cardiovascular event subtypes in both populations.

\begin{tabular}{lcccc}
\hline Type of Event & \multicolumn{2}{c}{ General Population, $\mathrm{n}=1869$} & \multicolumn{2}{c}{ RA Population, $\mathrm{n}=326$} \\
& \multicolumn{1}{c}{ Prevalent, $\mathrm{n=123}$} & Incident, $\mathrm{n}=257$ & Prevalent, $\mathrm{n}=48$ & Incident, $\mathrm{n}=95$ \\
\hline Myocardial infarction & 33 & 33 & 42 & 57 \\
Cerebrovascular accident & 17 & 17 & 17 & 20 \\
Transient ischemic attack & 5 & 6 & 17 & 76 \\
Peripheral arterial disease & 20 & 25 & 8 & 17 \\
Angina pectoris & 28 & 20 & N.A. \\
\hline
\end{tabular}

Data are in percentages. RA: rheumatoid arthritis; N.A.: not assessed; angina pectoris: chest pain preceding coronary artery bypass graft or percutaneous coronary intervention with stent placement, chest pain with significant ST segment deviation on electrocardiogram, chest pain preceding diagnosis of acute coronary syndrome, chest pain preceding coronary angiography with $>50 \%$ stenosis, chest pain preceding positive exercise test. Possibility of more than 1 event previous to baseline. 